\title{
Impact of Scribes on Physician Satisfaction, Patient Satisfaction, and Charting Efficiency: A Randomized Controlled Trial
}

\author{
Risha Gidwani, DrPH $\mathrm{H}^{1,2}$ \\ Catbina Nguyen, $\mathrm{MPH}^{3}$ \\ Alexis Kofoed, $\mathrm{MPH}^{2}$ \\ Catherine Carragee, $\mathrm{BA}^{2}$ \\ Tracy Rydel, $M D^{2}$ \\ Ian Nelligan, $M D, M P H^{2}$ \\ Amelia Sattler, $M D^{2}$ \\ Megan Maboney, $M D^{2}$ \\ Steven Lin, $M D^{2}$
}

${ }^{1}$ Center for Health Policy and Center for Primary Care and Outcomes Research, Stanford University School of Medicine, Stanford University, Stanford, California

${ }^{2}$ Division of Primary Care and Population Health, Department of Medicine, Stanford University School of Medicine, Stanford University, Stanford, California

${ }^{3}$ Division of Epidemiology, Department of Health Research and Policy, Stanford University School of Medicine, Stanford University, Stanford, California
Conflicts of interest: authors report none.

\section{CORRESPONDING AUTHOR}

Steven Lin, MD

Suite 405, 211 Quarry Rd

MC 5985

Palo Alto, CA 94304

stevenlin@stanford.edu

\begin{abstract}
PURPOSE Scribes are increasingly being used in clinical practice despite a lack of high-quality evidence regarding their effects. Our objective was to evaluate the effect of medical scribes on physician satisfaction, patient satisfaction, and charting efficiency.

METHODS We conducted a randomized controlled trial in which physicians in an academic family medicine clinic were randomized to 1 week with a scribe then 1 week without a scribe for the course of 1 year. Scribes drafted all relevant documentation, which was reviewed by the physician before attestation and signing. In encounters without a scribe, the physician performed all charting duties. Our outcomes were physician satisfaction, measured by a 5 -item instrument that included physicians' perceptions of chart quality and chart accuracy; patient satisfaction, measured by a 6 -item instrument; and charting efficiency, measured by time to chart close.
\end{abstract}

RESULTS Scribes improved all aspects of physician satisfaction, including overall satisfaction with clinic $(O R=10.75)$, having enough face time with patients $(\mathrm{OR}=3.71)$, time spent charting $(\mathrm{OR}=86.09)$, chart quality $(\mathrm{OR}=7.25)$, and chart accuracy $(O R=4.61)$ (all $P$ values <.001). Scribes had no effect on patient satisfaction. Scribes increased the proportion of charts that were closed within 48 hours $(\mathrm{OR}=1.18, P=.028)$.

CONCLUSIONS To our knowledge, we have conducted the first randomized controlled trial of scribes. We found that scribes produced significant improvements in overall physician satisfaction, satisfaction with chart quality and accuracy, and charting efficiency without detracting from patient satisfaction. Scribes appear to be a promising strategy to improve health care efficiency and reduce physician burnout.

Ann Fam Med 2017;15:427-433. https://doi.org/10.1370/afm.2122.

\section{INTRODUCTION}

E lectronic health records (EHRs) have radically transformed the practice of medicine. Driven by federal meaningful use incentives and penalties ${ }^{1,2}$ more than $95 \%$ of US hospitals and $56 \%$ of officebased physicians have adopted EHRs. ${ }^{3,4}$ Electronic health records hold promise to improve patient safety, quality of care, physician efficiency and performance, patient-physician communication, patient participation, cost of care, and health outcomes. ${ }^{5-9}$ There is also growing evidence, however, that in their current state, EHRs are associated with decreased physician productivity and revenue, ${ }_{1}^{10}$ negative patient-physician interactions and relationships, ${ }^{11}$ and widespread physician dissatisfaction. ${ }^{12-14}$

More than one-half of all US physicians experience burnout, with primary care physicians having one of the highest rates. ${ }^{15}$ Among the largest contributors to burnout is a growing clerical workload. ${ }^{16-18}$ For every hour physicians provide direct face time to patients, 2 more hours are spent on EHR and desk work. ${ }^{19}$ Many physicians leave most charting to the end of 
the day, and spend 1 to 2 hours each night working on the EHR. ${ }^{19}$

One strategy to decrease clerical burden is the use of scribes. Scribes are nonlicensed team members trained to document patient encounters in real time under the direct supervision of a physician. ${ }^{20}$ Scribes do not act independently but may assist with charting, recording laboratory and radiology results, and supporting physician workflow with EHR data entry. ${ }^{21}$ Although the use of scribes as physician extenders in emergency departments has been reported as early as the 1970s, it is only recently that the popularity of scribes has skyrocketed..$^{22}$ Scribes are currently being used in more than 1,000 hospitals and clinics across 44 states. ${ }^{23}$ It is estimated that by 2020 , there will be 100,000 scribes in the United States, or 1 scribe for every 9 physicians. ${ }^{23}$

Despite the increasing presence of scribes, methodologically rigorous studies regarding their impact are lacking. Two systematic reviews found, using data from observational studies, that scribes may improve revenue, patient and physician satisfaction, productivity, efficiency, and the quality of patient-physician interactions. ${ }^{24,25}$ There has been no randomized controlled study of scribes, and few studies have been undertaken in the primary care setting. Given that most office visits are to primary care physicians, ${ }^{26}$ research in this setting is particularly warranted.

\section{METHODS}

\section{Design}

Physicians were randomly assigned to 1 week practicing with a scribe then 1 week without a scribe for the course of 52 weeks. Randomization at the physicianweek level was chosen instead of randomizing at the level of patients, as variations in length of patient appointments posed challenges for proper allocation of scribes across patients and was too disruptive to normal clinic flow. We also chose not to randomize at the physician level, as the small number of physicians included in this study would not properly protect against imbalance in the scribe and no-scribe groups. During the week in which a physician was assigned a scribe, the scribe attended all appointments and drafted all relevant documentation, including the history and physical findings, objective examination findings, laboratory and radiology results, assessment and plan, and patient instructions. The physician reviewed the note, attested to its accuracy, and signed it before the chart was closed. During the week in which the physician was not assigned a scribe, the physician performed all charting duties. The EHR used was the outpatient version of Epic (Epic Systems Corporation).
The study was conducted from July 2015 to June 2016. Four physicians and 2 scribes participated in the study, which was undertaken in a family medicine clinic associated with a large academic medical center in Northern California. All physicians were board-certified in family medicine and had an average of 6 years of practice experience. None had prior experience working with scribes. As part-time clinicians, each physician in the study had 4, 4-hour clinic sessions per week when data were collected. Both scribes were college graduates who completed an 80 -hour training course administered by a commercial scribe company (Elite Medical Scribes). One scribe was assigned to 2 physicians in the first 6 months of the study; in the second 6 months, that scribe was assigned to the other 2 physicians. This allowed us to test for any learning effects that may have occurred in the physician-scribe dyads.

\section{Physician Satisfaction}

Physician satisfaction was measured by a selfadministered 5 -item questionnaire. Answers were recorded using a 7-point Likert scale, with a value of 1 indicating strong disagreement (strongly dissatisfied) and 7 indicating strong agreement (strongly satisfied). Physicians were offered 1 questionnaire after each 4-hour clinic session. For data analyses, we dichotomized each answer into strongly satisfied vs non-strongly satisfied ( 7 vs 1 to 6 ) because of skewness in results. In sensitivity analyses, we tested alternate ways to characterize the outcome by dichotomizing scores from 1 to 5 and 6 to 7 . To investigate the effect of scribes on aspects of physician satisfaction, each item was assessed using its own fixed-effects logistic regression equation with the physician questionnaire as the unit of analysis and accommodating multiple observations per physician. We adjusted for whether the interaction was new so we could test any learning effects over time within physician-scribe dyads. Specifically, we investigated whether a physician paired with a scribe had significantly lower satisfaction scores during the first quarter than during the second quarter that the same physician and scribe were paired. We adjusted for multiple hypothesis testing using the conservative Bonferroni correction, resulting in an $\alpha$ of $.01 .{ }^{27}$

\section{Patient Satisfaction}

Patient satisfaction was measured using a shortened, validated, 6-item questionnaire designed for the primary care setting. ${ }^{28}$ Each patient was asked to complete the questionnaire immediately after the appointment. To encourage completion, questionnaires were made anonymous. Answers were recorded using a 7-point Likert scale, with 1 indicating strong disagreement 
(strongly dissatisfied) and 7 indicating strong agreement (strongly satisfied). Each response was dichotomized into strongly satisfied (7) vs non-strongly satisfied (1 to 6) because of skewness of the distribution. In sensitivity analyses, we tested alternate ways to characterize the outcome, specifically dichotomizing scores from 1 to 5 and 6 to 7 . We investigated each item separately using its own fixed-effects logistic regression equation with the patient questionnaire as the unit of analysis, clustering questionnaires within physician. All tests were evaluated against a Bonferroni-corrected $\alpha$ of .007.

\section{Charting Efficiency}

Physician efficiency was measured as the time to chart close, which is calculated as the time from appointment start to the physician signing the chart note, which is marked by timestamps in the EHR. Industry standards (Medicare documentation guidelines) ${ }^{29}$ state that charts should be completed within 48 hours; therefore, we dichotomized time to close chart into 48 hours or less vs more than 48 hours. We ran fixed-effects logistic regression with chart as the unit of analysis, accommodating clustering of charts within physician.
This study was exempted from formal review by the Institutional Review Board of Stanford University School of Medicine.

\section{RESULTS}

\section{Physician Satisfaction}

A total of 361 physician satisfaction questionnaires were completed, for a $73.1 \%$ response rate (Table 1 ). Physicians were more likely to complete a questionnaire when a scribe was present $(53.2 \%)$ than when a scribe was not $(46.8 \%)$. Scribes produced significantly higher physician satisfaction in all aspects of care and charting (Tables 2-4). Physicians who worked with a scribe had 10.75 the adjusted odds of expressing high satisfaction with their clinic that day, 3.71 the adjusted odds of having enough face time with patients, and 86.09 the adjusted odds of expressing high satisfaction with the amount of time they spent charting (all $P<.001)$. Scribes increased physician satisfaction with the quality and accuracy of their charts. Physicians reported 7.25 the adjusted odds of being satisfied with their chart quality when a scribe was present $(P<.001)$. There was no difference in satisfaction with quality when the physician-scribe dyad was new vs established $(P=.451)$. Physicians reported 4.61 the adjusted odds of being satisfied with chart accuracy when a scribe was present $(P<.001)$. Physicians did report being less satisfied with chart accuracy when the physician-scribe dyad was new (adjusted $\mathrm{OR}=0.39$ ) vs established,

Table 2. Physician and Patient Questionnaire Results, Unadjusted

\begin{tabular}{|c|c|c|c|c|c|c|c|}
\hline \multirow[b]{2}{*}{ Characteristic } & \multicolumn{7}{|c|}{ Questionnaire Score ${ }^{a}$} \\
\hline & $\begin{array}{c}1 \\
\text { No. (\%) }\end{array}$ & $\begin{array}{c}2 \\
\text { No. }(\%)\end{array}$ & $\begin{array}{c}3 \\
\text { No. (\%) }\end{array}$ & $\begin{array}{c}4 \\
\text { No. (\%) }\end{array}$ & $\begin{array}{c}5 \\
\text { No. (\%) }\end{array}$ & $\begin{array}{c}6 \\
\text { No. (\%) }\end{array}$ & $\begin{array}{c}7 \\
\text { No. (\%) }\end{array}$ \\
\hline \multicolumn{8}{|l|}{ Physician questionnaire $(n=361)$} \\
\hline Overall satisfaction & $2(0.6)$ & $8(2.2)$ & $16(4.4)$ & $39(10.8)$ & $69(19.1)$ & $122(33.8)$ & $105(29.1)$ \\
\hline Face time with patients & $2(0.6)$ & $6(1.7)$ & $16(4.4)$ & $34(9.4)$ & $69(19.1)$ & $90(24.9)$ & $144(39.9)$ \\
\hline Chart quality & $3(0.8)$ & $5(1.4)$ & $14(3.9)$ & $27(7.5)$ & $69(19.1)$ & $114(31.6)$ & $129(35.7)$ \\
\hline Chart accuracy & $2(0.6)$ & $4(1.1)$ & $10(2.8)$ & $36(10.0)$ & $68(18.8)$ & $106(29.4)$ & $135(37.4)$ \\
\hline \multicolumn{8}{|l|}{ Patient questionnaire $(n=1,475)$} \\
\hline Physician explains things to me & $8(0.5)$ & $0(0.0)$ & $1(0.1)$ & $2(0.1)$ & $8(0.5)$ & $84(5.7)$ & $1,372(93.0)$ \\
\hline Physician listens to me & $8(0.5)$ & $0(0.0)$ & $1(0.1)$ & $3(0.2)$ & $10(0.7)$ & $67(4.5)$ & $1,386(94.0)$ \\
\hline Physician cares about me & $7(0.5)$ & $1(0.1)$ & $0(0.0)$ & $5(0.3)$ & $17(1.2)$ & $72(4.9)$ & $1,366(93.1)$ \\
\hline Physician spends enough time with me & $7(0.5)$ & $1(0.1)$ & $1(0.1)$ & $6(0.4)$ & $22(1.5)$ & $97(6.6)$ & $1,341(90.9)$ \\
\hline I would recommend this physician & $7(0.5)$ & $1(0.1)$ & $1(0.1)$ & $5(0.3)$ & $10(0.7)$ & $75(5.1)$ & $1,375(93.3)$ \\
\hline
\end{tabular}


but results were not significant using a Bonferronicorrected $\alpha$ of .01 $(P=.019)$. There was no difference in significance of the impact of scribes on physician survey results when we dichotomized the responses into 1 to 5 vs 6 to 7 .

Table 3. Physician Satisfaction, Unadjusted Results

\begin{tabular}{lcc}
\hline Characteristic & $\begin{array}{c}\text { Scribe Present } \\
\text { Median Score (IQR) }\end{array}$ & $\begin{array}{c}\text { Scribe Not Present } \\
\text { Median Score (IQR) }\end{array}$ \\
\hline Overall satisfaction & $6(6-7)$ & $5(4-6)$ \\
Face time with patients & $6.5(6-7)$ & $5(4-7)$ \\
Charting time & $6(6-7)$ & $4(3-5)$ \\
Chart quality & $6(6-7)$ & $5(5-6)$ \\
Chart accuracy & $6(6-7)$ & $6(5-7)$ \\
\hline lQR = interquartile range. & \\
a Responses scored on a scale from 1 to 7 where 1 indicates least satisfaction, and 7 indicates \\
most satisfaction.
\end{tabular}

Table 4. Physician Satisfaction, Adjusted Results

\begin{tabular}{|c|c|c|c|}
\hline Outcome & OR & $95 \% \mathrm{Cl}$ & $P$ Value \\
\hline \multicolumn{4}{|l|}{ Overall satisfaction } \\
\hline Scribe & 10.75 & $5.36-21.58$ & $<.001$ \\
\hline Physician 1, new interaction ${ }^{\mathrm{a}}$ & 0.51 & $0.27-0.96$ & .038 \\
\hline Physician 2 & 0.78 & $0.36-1.71$ & .539 \\
\hline Physician 3 & 1.49 & $0.71-3.12$ & .288 \\
\hline Physician 4 & 0.15 & $0.06-0.41$ & $<.001$ \\
\hline \multicolumn{4}{|l|}{ Face time with patients } \\
\hline Scribe & 3.71 & $1.91-7.21$ & $<.001$ \\
\hline Physician 1, new interaction ${ }^{a}$ & 0.73 & $0.37-1.46$ & .375 \\
\hline Physician 2 & 1.28 & $0.63-2.60$ & .498 \\
\hline Physician 3 & 4.71 & $2.35-9.44$ & $<.001$ \\
\hline Physician 4 & 0.11 & $0.04-0.31$ & $<.001$ \\
\hline \multicolumn{4}{|l|}{ Charting time } \\
\hline Scribe & 86.09 & $19.58-378.41$ & $<.001$ \\
\hline Physician 1, new interaction ${ }^{\mathrm{a}}$ & 1.04 & $0.56-1.96$ & .891 \\
\hline Physician 2 & 1.75 & $0.70-4.35$ & .228 \\
\hline Physician 3 & 1.31 & $0.55-3.16$ & .542 \\
\hline Physician 4 & 0.15 & $0.05-0.46$ & .001 \\
\hline \multicolumn{4}{|l|}{ Chart quality } \\
\hline Scribe & 7.25 & $3.42-15.39$ & $<.001$ \\
\hline Physician 1, new interaction ${ }^{a}$ & 0.75 & $0.36-1.55$ & .435 \\
\hline Physician 2 & 1.34 & $0.60-3.01$ & .475 \\
\hline Physician 3 & 10.18 & $4.53-22.85$ & $<.001$ \\
\hline Physician 4 & 0.13 & $0.04-0.44$ & .001 \\
\hline \multicolumn{4}{|l|}{ Chart accuracy } \\
\hline Scribe & 4.61 & $2.11-10.06$ & $<.001$ \\
\hline Physician 1, new interaction ${ }^{a}$ & 0.38 & $0.17-0.85$ & .018 \\
\hline Physician 2 & 0.81 & $0.36-1.81$ & .611 \\
\hline Physician 3 & 15.19 & $6.9-33.44$ & $<.001$ \\
\hline Physician 4 & 0.09 & $0.02-0.34$ & $<.001$ \\
\hline \multicolumn{4}{|l|}{$\mathrm{OR}=$ odds ratio } \\
\hline \multicolumn{4}{|l|}{ Note: Model B. } \\
\hline \multicolumn{4}{|c|}{ a First interaction between scribe and physician. } \\
\hline
\end{tabular}

\section{Patient Satisfaction}

A total of 1,475 patient satisfaction questionnaires were completed for an $87.7 \%$ response rate (Table 1). Patients were more likely to complete a questionnaire when a scribe was present (54.8\%) than when a scribe was not (45.2\%). In adjusted analyses, there were no significant differences in any aspect of patient satisfaction between physician visits in which a scribe was or was not present (Table 2 and Table 5). Satisfaction across patient questionnaires, however, was high with or without a scribe, with more than $91 \%$ of patients in either group reporting being highly satisfied with their care. There was no difference in significance of the impact of scribes on patient survey results when we dichotomized the responses into 1 to 5 vs 6 to 7 .

\section{Charting Efficiency}

Scribes improved time to close chart. In unadjusted analyses, $28.5 \%$ of charts that were drafted by physicians were closed in 48 hours relative to $32.6 \%$ of charts drafted by scribes. In adjusted analyses, scribed charts had 1.18 the adjusted odds of being closed within 48 hours compared with physicianonly charts $(P=.028)$ (Table 6$)$.

\section{DISCUSSION}

To our knowledge, we have undertaken the first randomized controlled trial evaluating the effects of medical scribes. We found that scribes significantly improved physician satisfaction across all measured aspects of patient care and documentation. Scribes improved physician-perceived chart quality and chart accuracy, as well as charting efficiency as measured by the likelihood of closing a chart within 48 hours.

When working with a scribe, physicians were much more satisfied with how their clinic went, the length of time they spent face-to-face with patients, and the time they spent charting. These findings suggest that scribes may have a protective effect on physicians' well-being. Implementation of team documentation is an important component of achieving the Quadruple Aim, ${ }^{30}$ a patient-centered approach to care that also emphasizes improving the work life of physicians. Spending less time on documentation frees up the physician to pursue direct clini- 
cal care and care coordination, thus enhancing joy of practice and preventing burnout. In academic centers, scribes provide faculty physicians more time to teach medical students and residents. ${ }^{31}$

We found that not only were physicians satisfied with the quality and accuracy of charting done by scribes, they were more satisfied with scribed charts than with their own. This finding is consistent with a study suggesting that scribed notes are of higher quality than physician-only notes. ${ }^{32}$ Patient encounters in primary care are often highly complex; scribes enable physicians to capture all the important details in the

\section{Table 5. Patient Satisfaction, Adjusted Results}

\begin{tabular}{|c|c|c|c|}
\hline Outcome & OR & $95 \% \mathrm{Cl}$ & $P$ Value \\
\hline \multicolumn{4}{|l|}{ Physician explains things to me } \\
\hline Scribe & 0.82 & $0.48-1.40$ & .468 \\
\hline Physician 1 , new interaction ${ }^{a}$ & 0.81 & $0.48-1.36$ & .429 \\
\hline Physician 2 & 0.40 & $0.22-0.71$ & .002 \\
\hline Physician 3 & 1.54 & $0.72-3.32$ & .266 \\
\hline Physician 4 & 0.97 & $0.50-1.87$ & .920 \\
\hline \multicolumn{4}{|l|}{ Physician listens to me } \\
\hline Scribe & 0.88 & $0.49-1.58$ & .681 \\
\hline Physician 1 , new interaction ${ }^{a}$ & 0.75 & $0.42-1.32$ & .319 \\
\hline Physician 2 & 0.64 & $0.36-1.11$ & .113 \\
\hline Physician 3 & 2.63 & $1.18-5.87$ & .018 \\
\hline Physician 4 & 1.58 & $0.82-3.04$ & .717 \\
\hline \multicolumn{4}{|l|}{ Physician cares about me } \\
\hline Scribe & 1.15 & $0.67-1.97$ & .609 \\
\hline Physician 1 , new interaction ${ }^{a}$ & 0.66 & $0.38-1.13$ & .130 \\
\hline Physician 2 & 0.39 & $0.22-0.69$ & .001 \\
\hline Physician 3 & 2.19 & $0.96-5.00$ & .061 \\
\hline Physician 4 & 0.79 & $0.43-1.47$ & .459 \\
\hline \multicolumn{4}{|l|}{ Physician encourages me to talk } \\
\hline Scribe & 1.07 & $0.63-1.80$ & .808 \\
\hline Physician 1 , new interactiona & 0.58 & $0.35-0.97$ & .037 \\
\hline Physician 2 & 0.39 & $0.22-0.68$ & .001 \\
\hline Physician 3 & 2.09 & $0.95-4.60$ & .068 \\
\hline Physician 4 & 0.68 & $0.38-1.23$ & .202 \\
\hline \multicolumn{4}{|l|}{$\begin{array}{l}\text { Physician spends enough time } \\
\text { with me }\end{array}$} \\
\hline Scribe & 1.12 & $0.70-1.79$ & .642 \\
\hline Physician 1 , new interaction ${ }^{a}$ & 0.92 & $0.06-1.50$ & .725 \\
\hline Physician 2 & 0.53 & $0.33-0.85$ & .008 \\
\hline Physician 3 & 3.20 & $1.57-6.53$ & .001 \\
\hline Physician 4 & 1.55 & $0.90-2.68$ & .116 \\
\hline \multicolumn{4}{|l|}{ I would recommend this physician } \\
\hline Scribe & 1.06 & $0.60-1.89$ & .825 \\
\hline Physician 1 , new interaction ${ }^{a}$ & 0.59 & $0.34-1.04$ & .066 \\
\hline Physician 2 & 0.34 & $0.18-0.62$ & .001 \\
\hline Physician 3 & 1.79 & $0.76-4.19$ & .183 \\
\hline Physician 4 & 0.75 & $0.38-1.47$ & .405 \\
\hline \multicolumn{4}{|l|}{ OR $=$ odds ratio } \\
\hline \multicolumn{4}{|l|}{ Note: Model B. } \\
\hline a First interaction between scribe an & & & \\
\hline
\end{tabular}

note while communicating effectively with the patient in the room.

During a typical day in the ambulatory setting, $49 \%$ of physician time is spent on EHR and desk work, whereas only $27 \%$ is spent face-to-face with patients. ${ }^{19}$ Physicians can use EHR shortcuts, such as copy and paste ${ }^{33}$ but these actions are associated with a risk of documentation error that can jeopardize patient safety. ${ }^{34,35}$ In addition, documentation competes with panel management and EHR inbox completion. It is estimated that the average primary care physician receives 76.9 EHR inbox notifications daily, requiring an investment of approximately 66.8 minutes per day. ${ }^{36}$ Eliminating the burden of writing notes affords more time for physicians to attend to the tasks of panel management during, not after, their workday.

Our study found no difference in patient satisfaction between visits with or without a scribe, perhaps because of ceiling effects; patients expressed high satisfaction both during visits with and without a scribe. Nevertheless, we found that the presence of a scribe did not decrease patient satisfaction. This finding has been found in other nonrandomized studies, even in settings as sensitive as a urology practice. ${ }^{37}$

Our study is the first to evaluate charting efficiency in a randomized controlled manner. We found that scribed charts were more likely to be closed within 48 hours compared with charts completed by physicians alone. Charts that are completed in a timely manner allow patient data to be accessed by other physicians in the health care system, which is particularly important to safety and effective care coordination. Charts completed in a timely manner may also be more accurate than those completed multiple days after the patient's visit.

This randomized controlled trial was conducted at a single family medicine clinic in an academic medical center. Although our unit of analysis was a physicians' day or patient encounter, our study's biggest limitation is the relatively few physicians and scribes. Our findings are positive with respect to physician satisfaction and efficiency, but future randomized studies should be conducted with large sample sizes and across multiple institutions to improve the generalizability of these findings. The physician satisfaction instrument we used measured markers related to joy of practice and was deemed feasible 
Table 6. Charting Efficiency, Adjusted Results for Less Than 48 Hours to Close Chart

\begin{tabular}{lccc}
\hline Variable & OR & $\mathbf{9 5 \% ~ C l}$ & $P$ Value \\
\hline Scribe & 1.18 & $1.02-1.36$ & .028 \\
$\begin{array}{l}\text { Physician 1, new } \\
\quad \text { interaction }\end{array}$ & 1.01 & $0.86-1.18$ & .950 \\
$\begin{array}{l}\text { Physician 2 } \\
\text { Physician 3 }\end{array}$ & 6.26 & $5.04-7.76$ & $<.001$ \\
Physician 4 & 8.35 & $6.75-10.33$ & $<.001$ \\
\hline
\end{tabular}

$\mathrm{OR}=$ odds ratio

Note: Model B.

a First interaction between scribe and physician.

for repeated use, but it was not a validated survey of joy of practice or burnout. Our findings of improved efficiency, as measured by time to chart close, would be strengthened by future work using other objective approaches, such as time and motion analyses. Our data show that physicians reported higher satisfaction with the quality and accuracy of charting when scribes were present ${ }_{i}$ future work should evaluate chart quality in an objective way with blinded observers using a validated instrument. We also found that patient satisfaction was not affected by the presence of a scribe, but we believe that qualitative work would better elucidate patients' perceptions of scribes. Other worthy avenues of research include evaluating team-based care models using medical assistants or nurses as scribes, ${ }^{38}$ the effect of scribes on physician productivity and revenue, as well as cost-benefit analyses, which have been described by others ${ }^{39-41}$ but warrant further research in the primary care setting.

The challenge of modifying physicians' practices to accommodate EHRs without sacrificing quality of care or quality of physician-patient interactions is not trivial. Some have suggested that scribes are not an appropriate solution, arguing that they are no substitute for better functioning EHRs or may remove some of the pressure on EHR designers to improve their systems. ${ }^{23}$ We agree that scribes are not a replacement for EHR redesign, but we do consider them an immediate solution that can be implemented while the more onerous and timeconsuming problem of EHR redesign is also tackled. We also believe scribes can serve as a complement to a high-functioning EHR, as the latter will still require the mundane capture of information that does not require a physician. By reducing the time that physicians spend on clerical tasks, scribes serve an important function in a multidisciplinary health care team.

To read or post commentaries in response to this article, see it online at http://www.AnnFamMed.org/content/15/5/427.
Key words: medical scribes; electronic health records; work satisfaction; patient satisfaction; efficiency; primary care physicians; randomized controlled trial

Submitted December 6, 2016; submitted, revised, April 15, 2017; accepted May 3, 2017.

Funding support: This study was supported by a grant to the senior author (S.L.) from the Pisacano Leadership Foundation, the philanthropic foundation of the American Board of Family Medicine.

Disclaimer: The Foundation had no role in the design of the study; the collection, analysis, and interpretation of the data; and the decision to approve publication of the finished manuscript.

Previous presentations: A portion of this manuscript was presented at the Starfield Summit, April 23-26, 2016, Washington, DC; and the Society of Teachers of Family Medicine (STFM) Annual Spring Conference, April 30-May 4, 2016, Minneapolis, Minnesota.

Acknowledgments: The authors wish to thank Sang-ick Chang, MD, $\mathrm{MPH}$, associate dean for primary care; Tim Engberg, RN, MA, vice president for primary care; Juno Vega, RN, clinic manager; and Therese Truong, RN, assistant clinic manager, for their support of the scribe program.

\section{References}

1. Blumenthal D. Wiring the health system-origins and provisions of a new federal program. N Engl J Med. 2011;365(24):2323-2329.

2. Blumenthal D. Implementation of the federal health information technology initiative. N Engl J Med. 2011;365(25):2426-2431.

3. Office of the National Coordinator for Health Information Technology. Hospitals Participating in the CMS EHR Incentive Programs, Health IT Quick-Stat \#45. http://dashboard.healthit.gov/quickstats/ pages/FIG-Hospitals-EHR-Incentive-Programs.php. Updated Feb 2016. Accessed Nov 1, 2016.

4. Office of the National Coordinator for Health Information Technology. Office-based Health Care Professionals Participating in the CMS EHR Incentive Programs, Health IT Quick-Stat \#44. http://dashboard.healthit.gov/quickstats/pages/FIG-Health-CareProfessionals-EHR-Incentive-Programs.php. Updated Feb 2016. Accessed Nov 1, 2016.

5. Institute of Medicine, Committee on Patient Safety and Health Information Technology. Health IT and Patient Safety: Building Safer Systems for Better Care. Washington, DC: National Academies Press; 2011.

6. Holroyd-Leduc JM, Lorenzetti D, Straus SE, Sykes L, Quan H. The impact of the electronic medical record on structure, process, and outcomes within primary care: a systematic review of the evidence. J Am Med Inform Assoc. 2011;18(6):732-737.

7. King J, Patel V, Jamoom EW, Furukawa MF. Clinical benefits of elec tronic health record use: national findings. Health Serv Res. 2014; 49(1 Pt 2):392-404.

8. Health IT. gov. Benefits of electronic health records (EHRs). http:// www.healthit.gov/providers-professionals/benefits-electronic-healthrecords-ehrs. Updated Jul 2015. Accessed Nov 1, 2016.

9. Slight SP, Berner ES, Galanter W, et al. Meaningful use of electronic health records: experiences from the field and future opportunities. JMIR Med Inform. 2015;3(3):e30.

10. Fleming NS, Becker ER, Culler SD, et al. The impact of electronic health records on workflow and financial measures in primary care practices. Health Serv Res. 2014;49(1 Pt 2):405-420. 
11. Shachak A, Reis $S$. The impact of electronic medical records on patient-doctor communication during consultation: a narrative literature review. J Eval Clin Pract. 2009;15(4):641-649.

12. Friedberg MW, Chen PG, Van Busum KR, et al. Factors Affecting Physician Professional Satisfaction and Their Implications for Patient Care, Health Systems, and Health Policy. Santa Monica, CA: Rand Corporation; 2013.

13. Menachemi N, Collum TH. Benefits and drawbacks of electronic health record systems. Risk Manag Healthc Policy. 2011;4:47-55.

14. Boonstra A, Broekhuis M. Barriers to the acceptance of electronic medical records by physicians from systematic review to taxonomy and interventions. BMC Health Serv Res. 2010;10:231.

15. Shanafelt TD, Hasan O, Dyrbye LN, et al. Changes in burnout and satisfaction with work-life balance in physicians and the general US working population between 2011 and 2014. Mayo Clin Proc. 2015; 90(12):1600-1613.

16. Gottschalk A, Flocke SA. Time spent in face-to-face patient care and work outside the examination room. Ann Fam Med. 2005;3(6):488-493.

17. Gilchrist V, McCord G, Schrop SL, et al. Physician activities during time out of the examination room. Ann Fam Med. 2005;3(6):494-499.

18. Chen MA, Hollenberg JP, Michelen W, Peterson JC, Casalino LP. Patient care outside of office visits: a primary care physician time study. J Gen Intern Med. 2011;26(1):58-63.

19. Sinsky C, Colligan L, Li L, et al. Allocation of physician time in ambulatory practice: a time and motion study in 4 specialties. Ann Intern Med. 2016;165(11):753-760.

20. Campbell LL, Case D, Crocker JE, et al. Using medical scribes in a physician practice. J AHIMA. 2012;83(11):64-69.

21. Joint Commission. Clarification: Safe use of scribes in clinical settings. Jt Comm Perspect. 2011;31(6):4-5.

22. Lin S, Khoo J, Schillinger E. Next big thing: integrating medical scribes into academic medical centres. BMJ Simulation \& Tech Enhanced Learning. 2016;2(2):27-29.

23. Gellert GA, Ramirez R, Webster SL. The rise of the medical scribe industry: implications for the advancement of electronic health records. JAMA. 2015;313(13):1315-1316.

24. Shultz CG, Holmstrom HL. The use of medical scribes in health care settings: a systematic review and future directions. J Am Board Fam Med. 2015;28(3):371-381.

25. Heaton HA, Castaneda-Guarderas A, Trotter ER, Erwin PJ, Bellolio MF. Effect of scribes on patient throughput, revenue, and patient and provider satisfaction: a systematic review and meta-analysis. Am J Emerg Med. 2016;34(10):2018-2028.

26. Centers for Disease Control and Prevention. National Ambulatory Medical Care Survey: 2012 State and National Summary Tables. http://www.cdc.gov/nchs/data/ahcd/namcs_summary/2012_namcs_ web_tables.pdf. Updated 2012. Accessed Nov 1, 2016.
27. Bland JM, Altman DG. Multiple significance tests: the Bonferroni method. BMJ. 1995;310(6973):170.

28. Hojat M, Louis DZ, Maxwell K, Markham FW, Wender RC, Gonnella JS. A brief instrument to measure patients' overall satisfaction with primary care physicians. Fam Med. 2011;43(6):412-417.

29. Centers for Medicare and Medicaid Services. Medicare Claims Processing Manual. Chapter 12 - Physicians/Nonphysician Practitioners. http://www.cms.gov/Regulations-and-Guidance/Guidance/ Manuals/Downloads/clm104c12.pdf. Updated Mar 2016. Accessed Nov 1, 2016.

30. Bodenheimer T, Sinsky C. From triple to quadruple aim: care of the patient requires care of the provider. Ann Fam Med. 2014;12(6):573-576.

31. Hess JJ, Wallenstein J, Ackerman JD, et al. Scribe impacts on provider experience, operations, and teaching in an academic emergency medicine practice. West J Emerg Med. 2015;16(5):602-610.

32. Misra-Hebert AD, Amah L, Rabovsky A, et al. Medical scribes: How do their notes stack up? J Fam Pract. 2016;65(3):155-159.

33. O'Donnell HC, Kaushal R, Barrón Y, Callahan MA, Adelman RD, Siegler EL. Physicians' attitudes towards copy and pasting in electronic note writing. J Gen Intern Med. 2009;24(1):63-68.

34. Siegler EL, Adelman R. Copy and paste: a remediable hazard of electronic health records. Am J Med. 2009;122(6):495-496.

35. Markel A. Copy and paste of electronic health records: a modern medical illness. Am J Med. 2010;123(5):e9.

36. Murphy DR, Meyer AN, Russo E, Sittig DF, Wei L, Singh H. The burden of inbox notifications in commercial electronic health records. JAMA Intern Med. 2016;176(4):559-560.

37. Koshy S, Feustel PJ, Hong M, Kogan BA. Scribes in an ambulatory urology practice: patient and physician satisfaction. J Urol. 2010; 184(1):258-262.

38. Yan C, Rose S, Rothberg MB, Mercer MB, Goodman K, MisraHebert AD. Physician, scribe, and patient perspectives on clinical scribes in primary care. J Gen Intern Med. 2016;31(9):990-995.

39. Bank AJ, Obetz C, Konrardy A, et al. Impact of scribes on patient interaction, productivity, and revenue in a cardiology clinic: a prospective study. Clinicoecon Outcomes Res. 2013;5:399-406.

40. Bank AJ, Gage RM. Annual impact of scribes on physician productivity and revenue in a cardiology clinic. Clinicoecon Outcomes Res. 2015;7:489-495.

41. Walker KJ, Dunlop W, Liew D, et al. An economic evaluation of the costs of training a medical scribe to work in Emergency Medicine. Emerg Med J. 2016;33(12):865-869. 